Article

\title{
Motivations Influencing Caffeine Consumption Behaviors among College Students in Korea: Associations with Sleep Quality
}

\author{
Jinkyung Choi \\ Department of Foodservice Management, Woosong University, Daejeon 34606, Korea; choi3728@wsu.ac.kr; \\ Tel.: +82-42-630-9253
}

Received: 18 January 2020; Accepted: 24 March 2020; Published: 30 March 2020

\begin{abstract}
Caffeinated beverages are a part of daily life. Caffeinated beverages such as coffee, tea, energy drinks, and soft drinks are easy to purchase and are frequently consumed by young college students. Moreover, smoking influences the consumption of caffeinated beverages. The concentration of caffeine in these products is an attractive factor for individuals that desire the effects of caffeine; however, abusing such products may lead to poor sleep quality. The motivations that drive caffeinated beverage consumption were investigated in this study through a survey. Self-reported questionnaires were distributed on campus to students enrolled at a university in Korea. The motivations of the students for consuming each caffeinated beverage and their sleep quality were investigated. The results of exploratory factor analysis showed the motivations for caffeinated beverage consumption were alertness, taste, mood, socialization, health benefits, and habit. The motivations for consuming each caffeinated beverage product were different. For instance, coffee consumption was motivated by a desire for alertness $(\mathrm{B}=0.107, \mathrm{SE}=0.049, \mathrm{t}=2.181, p<0.05)$ and by habit $(\mathrm{B}=0.345, \mathrm{SE}=0.046$, $t=7.428, p<0.001)$, whereas tea consumption was influenced by socialization $(B=0.142, S E=0.060$, $\mathrm{t}=2.357, p<0.05)$. Energy drink consumption was motivated by a desire for alertness $(\mathrm{B}=0.100$, $\mathrm{SE}=0.034, \mathrm{t}=2.966, p<0.01)$ and health benefits $(\mathrm{B}=0.120, \mathrm{SE}=0.051, \mathrm{t}=2.345, p<0.05)$, while the consumption of soft drinks was not motivated by any specific factors. Caffeinated beverage consumption did not show a significant relationship with sleep quality, although the general sleep quality of the respondents was poor. Smoking status showed significant differences in coffee and tea consumption as well as sleep quality. Smokers had a higher intake of coffee and a lower intake of tea than non-smokers. No interaction effect between smoking and coffee on sleep quality was found. Labeling detailing the amount of caffeine in products is necessary and a cautionary statement informing consumers that smoking cigarettes enhances the effects of caffeine should be included.
\end{abstract}

Keywords: caffeine; caffeinated beverage; motivation; sleep quality; consumption

\section{Introduction}

Caffeine is part of our diet and is often consumed in different types of drinks and food such as coffee beans, tea leaves, cocoa beans, kola nuts, and other plants [1]. The average caffeine intake per day is approximately $128.8 \mathrm{mg}$ in Korea [2] and between 210 and $238 \mathrm{mg}$ for Americans through various types of food including caffeinate beverages [3]. Additionally, $89 \%$ of adults in the U.S. drink caffeinated beverages on a daily basis in the form of coffee (64\%), soft drinks (18\%), and tea (16\%) [4], and Koreans have similar patterns [5]. Most consumers surveyed consumed caffeinated beverages, with $98 \%$ of all caffeinated beverages consumed as coffee, tea, soft drinks, and energy drinks, and coffee being the primary source of caffeine in the adult diet in many countries [4-8]. Coffee is the most common caffeinated beverage available to consumers [8] and is one of the most popular caffeinated 
beverages in Korea, with sales of 11 trillion and 7 hundred billion won in 2017, increasing from 3 trillion won in 2007 [9]. Caffeinated beverages have gained increasing popularity, especially among young generations, as lifestyles have become more Westernized. Food and beverage consumption trends indicate coffee is a preferred food rather than a functional food containing caffeine. However, most consumers are not aware of the amount of caffeine in their caffeinated drinks or its effects on them [8].

Factors associated with caffeine can be categorized as alertness, withdrawal symptoms, socializing, sensory effects, etc. Young generations, for example, most college students, consume caffeine to feel more awake, enjoy the taste, socialize, increase their physical energy [10], improve their mood, and alleviate stress [11]. Energy drinks are another type of caffeinated beverage popular among college students and the reasons for consuming energy drinks are frequently listed as increasing energy or counteracting insufficient sleep [10]. Among the many effects of caffeine, the enhancement of physical performance was reported in the early 20th century [12] and athletes frequently take advantage of caffeine as a stimulant $[7,13]$. The most common reason for taking caffeine is to feel more awake [11]. Caffeine is rapidly absorbed as quickly as 45 to $60 \mathrm{~min}$ [3] or 1-1.5 hours following ingestion and the absorbed caffeine is disseminated throughout the entire body, crossing the blood-brain barrier [1].

Nicotine can increase the speed of caffeine metabolism by almost 50\% [14]. Previous literature has shown that smoking enhances caffeine metabolism, which also accelerates caffeine clearance [1]. The effects of caffeine on performance occur through adenosine receptors, which are related to the brain and are associated with sleep, arousal, and cognition $[15,16]$. In addition, the sensory elements of coffee have a societal impact, inducing mood changes [17]. According to an analysis of previous literature by $\mathrm{O}^{\prime}$ Callahan [18], the positive and negative effects of caffeine coexist.

Although caffeine has some positive effects on general performance including physical and non-physical aspects, there are several negative side effects of taking caffeine. A study examined the effect of caffeine on 15,686 adolescents and found that students with high caffeine intake were more likely to feel worn-out compared to those who consumed less caffeine [19]. In addition, caffeinated energy drinks may be related to methylxanthine, which influences memory, anxiety, and sleep [7,10,20]. The consequences of taking caffeine can lead to insufficient sleep both in quality and quantity, which may result in the consumption of caffeine again to overcome the symptoms caused by the lack of sleep.

Laboratory studies have shown that a deficit in nocturnal sleep of as little as 90 min for just one night can lead to a one-third reduction in daytime objective alertness [21]. In another study investigating the effects of caffeine on sleep regulation, participants were administered $200 \mathrm{mg}$ of caffeine early in the morning at $7 \mathrm{a} . \mathrm{m}$. and monitored throughout the day. The caffeine significantly affected sleep efficiency as well as the total sleep time [22]. A mathematical model was developed to predict sleep reaction time according to the caffeine dose [23]. A study investigated the effectiveness of caffeinated beverages on excessive daytime sleepiness and sleep duration and found that participants who consumed more coffee had a shorter sleep duration (equal to or less than 6 hours) [24]. Despite the disadvantages of caffeinated beverages, consumers often ignore the negative effects of caffeine. These effects have inspired cautionary actions such as the recommendation of a maximum amount of caffeine consumption.

In Korea, the daily maximum intake of caffeine is $400 \mathrm{mg}$ for adults and $300 \mathrm{mg}$ for pregnant women [25]. The EU also recommends a maximum intake of $400 \mathrm{mg}$ for adults and $200 \mathrm{mg}$ for pregnant women [26]. Coffee contains the highest amount of caffeine (40-259 mg) among foods and beverages, followed by energy drinks ( $42-141 \mathrm{mg}$ ), teas ( $30-80 \mathrm{mg}$ ), soft drinks (36-71 mg), and chocolate products (12-25 mg) [27,28]. The EU requires a 'high caffeine content' label for products with caffeine in excess of $150 \mathrm{mg}$ [28]. The US FDA does not require the amount of caffeine be displayed but caffeine must be listed as a product [29]. Recently, the Korean National Food and Drug Administration implemented a new requirement of labeling the total amount of caffeine in products including café-made coffee in order to prevent caffeine overdose [5].

Despite the popularity and the prevalence of consumption, only a few studies have investigated caffeinated beverage consumption behaviors [30]. With increasing concerns about the over-consumption 
of caffeine, it is essential to investigate the reasons why people consume caffeinated beverages. Understanding the motivation for consuming caffeinated beverages will lead to more effective regulations for labeling such information on products, increasing the success of advising consumers about high caffeine consumption. Consuming a product without knowing how much caffeine it contains may cause other problems as caffeine has both advantageous and disadvantageous effects. Hence, the purpose of this study was two-fold. First, the motivation for consuming caffeine was investigated among college students. Second, the relationship between the consumption of caffeine and the quality of sleep was evaluated.

\section{Materials and Methods}

\subsection{Participants}

Quantitative methods were used in this study to collect data from the respondents. Before conducting the survey, the study was screened and approved by the institutional review board (1041549-191011-SB-80) at Woosong University. A survey was administered to college students in Korea for about four weeks. The survey was conducted on campus and was given to students enrolled at the University of Daejeon in Korea. The purpose of the survey was explained to the study participants and the survey proceeded after the respondents provided consent. The questionnaire was self-administered in a paper-based form and completed voluntarily without incentives. A total of 420 questionnaires were distributed to students and 404 were returned. Respondents were asked if they had consumed caffeine within the last month and 12 who had not consumed caffeine during this period were excluded. After screening, another 11 students were excluded due to incomplete responses and the remaining 381 were included in further analyses.

\subsection{Measures}

The participants were asked about their motivations for consuming caffeinated beverages and the questions were adapted from previous studies [30,31]. The questions were presented with a 5-point Likert scale (1: never 5: always). The consumption frequency and the most consumed caffeinated beverages were evaluated. The categories for caffeinated beverage were coffee, tea, energy drinks, and soft drinks and others (chocolate/cocoa drinks), which were taken from a previous study [24] [5,29]. In addition, the times when caffeinated beverages were usually consumed were evaluated. Along with caffeinated beverage consumption behaviors, the sleep quality of the respondents was investigated. In order to measure the quality of sleep, questions from the Pittsburgh Sleep Quality Index (PSQI) [32] were used. Questions such as their usual bed time, number of minutes until they fell asleep, usual wake up time, and hours of actual sleep were asked. Other questions were asked with four scales (not during the past month, less than once a week, once or twice a week, three or more times a week) such as during the past month, (1) how often have you had trouble sleeping because you ... ; (2) cannot get to sleep within $30 \mathrm{~min}$; (3) wake up in the middle of the night or early morning, etc. All questions were excerpted from a previous study [33]. Lastly, the demographic information of the respondents was collected.

\subsection{Data Analysis}

Data were coded using Excel and analyzed with the Statistical Package for the Social Sciences (SPSS, version 25, IBM Corp, 2018). An exploratory factor analysis (EFA) using the maximum likelihood method with the varimax rotation was conducted to identify the factor structure of 36 items related to the motivations for caffeinated beverage consumption by the respondents. The correlations of the extracted factors and their Cronbach's alpha were determined to evaluate the validity and internal consistency. Descriptive analyses were conducted to investigate the caffeinated beverage consumption behaviors of the students. In addition, analysis of variance (ANOVA) and Tukey's test were used to compare each factor in the demographic characteristics. 
Multiple regression analysis was performed on each category of caffeinated beverages (coffee, tea, energy drinks, soft drinks and others) in order to determine the effectiveness of the motivation factors. All categories of caffeinated beverages were dependent variables and the motivation factors were independent variables. Multiple regression analysis was performed simultaneously for all categories. The frequency of caffeinated beverage consumption was calculated as the sum of the consumption frequencies for all four categories of caffeinated beverage and divided into two groups based on the mean value. An independent $t$-test was conducted on the sleep quality of the low and high-caffeinated beverage consumption groups using PSQI. Lastly, descriptive analysis was performed on the demographic characteristics of the college students.

\section{Results}

\subsection{Demographic and Caffeinated Beverage Consumption Characteristics}

Table 1 presents the demographic characteristics of the respondents. One hundred and seventy-two of the respondents were men (45.6\%) and 205 were women (54.4\%). All respondents were single. About $35.8 \%$ of the respondents were freshmen and $30.8 \%$ were sophomores. The majority of the respondents were 20 years old $(30.2 \%)$ and 21 years old $(21.2 \%)$. More than two-thirds of the respondent reported that they lived alone (71.4\%). The majority of the respondents did not smoke (79.3\%) and $76.7 \%$ of those who smoked were male. In comparisons of caffeinated beverage consumption by gender, only coffee consumption showed a significant difference. Male students (Mean $[\mathrm{M}]=1$, standard deviation $[S D]=0.872)$ consumed more coffee than female students $(\mathrm{M}=0.81, \mathrm{SD}=0.785, \mathrm{t}=2.229, p<0.05)$. Tea, energy drinks, and soft drinks and others did not show any differences by gender. The consumptions of the four caffeinated beverages were compared according to smoking status. Coffee $(\mathrm{t}=3.604, p<0.001)$ and tea consumption $(\mathrm{t}=-2.897, p<0.01)$ significantly differed by smoking status. Smokers $(\mathrm{M}=1.22$, $\mathrm{SD}=0.815)$ had higher coffee consumption than non-smokers $(\mathrm{M}=0.83, \mathrm{SD}=0.831)$. The opposite pattern was observed for tea consumption, with non-smokers $(\mathrm{M}=0.5, \mathrm{SD}=0.809)$ consuming more tea than smokers $(\mathrm{M}=0.26, \mathrm{SD}=0.598)$. The consumption of energy drinks and soft drinks showed insignificant differences between smokers and non-smokers.

Caffeinated beverage consumption behaviors are shown in Table 2. The majority of the respondents consumed coffee $(45.4 \%)$, followed by soft drinks and others $(26.49 \%)$. The consumption of tea $(7.79 \%)$ and energy drinks (6.5\%) was relatively low. Most respondents consumed coffee once a day (46.7\%) and a smaller proportion consumed coffee twice a day (14.4\%). One hundred and thirty-one (34.4\%) respondents reported not drinking coffee every day. For tea, 25.2\% of the respondents reported consumption once a day and $66.7 \%$ did not consume tea. For energy drinks, the majority of respondents did not consume the beverages every day (88.5\%) and $8.7 \%$ consumed energy drinks once a day. Similar to coffee, the majority of respondents consumed soft drinks and others once a day $(43.3 \%)$ followed by two times a day $(12.9 \%)$.

The times when caffeinated beverages were consumed varied. The highest proportions of respondents consumed caffeinated beverages between 14:00 and 16:00 (24.4\%), followed by between 12:00 and 14:00 (20.1\%). Other time periods for consuming caffeinated beverages were almost equally distributed between 16:00-18:00 (13.2\%), 18:00-20:00 (14.8\%), and after 20:00 (16.6\%). The lowest proportion of respondents consumed caffeinated beverages between 07:00-10:00 (6.3\%), followed by between 10:00-12:00 (4.7\%). 
Table 1. Demographic characteristics and caffeinated beverage consumption behaviors $(n=381)$.

\begin{tabular}{|c|c|c|c|c|c|c|c|}
\hline \multicolumn{2}{|c|}{ Characteristics } & \multirow[t]{2}{*}{ Frequency (\%) } & Caffeine Consumption * & Coffee & Tea & Energy Drinks & Soft Drinks and Others \\
\hline & & & \multicolumn{5}{|c|}{ Mean \pm Standard Deviation } \\
\hline \multirow[t]{3}{*}{ Gender } & Male & $172(45.6)$ & $2.331 \pm 1.552$ & $1.00 \pm 0.872^{\mathrm{a}}$ & $0.39 \pm 0.745$ & $0.18 \pm 0.429$ & $0.76 \pm 0.828$ \\
\hline & Female & $205(54.4)$ & $2.312 \pm 1.572$ & $0.81 \pm 0.785^{b}$ & $0.53 \pm 0.820$ & $0.11 \pm 0.434$ & $0.860 \pm 0.858$ \\
\hline & Missing & 4 & & & & & \\
\hline \multirow[t]{3}{*}{ Marital status } & Married & $0(0)$ & & & & & \\
\hline & Single & $377(100)$ & $2.321 \pm 1.561$ & $0.90 \pm 0.830$ & $0.46 \pm 0.788$ & $0.14 \pm 0.432$ & $0.82 \pm 0.845$ \\
\hline & Missing & 4 & & & & & \\
\hline \multirow[t]{5}{*}{ Grade } & Freshman & $135(35.8)$ & $2.289 \pm 1.450$ & $0.84 \pm 0.775$ & $0.42 \pm 0.738$ & $0.16 \pm 0.403$ & $0.87 \pm 0.796$ \\
\hline & Sophomore & $116(30.8)$ & $2.285 \pm 1.651$ & $0.81 \pm 0.790$ & $0.52 \pm 0.807$ & $0.11 \pm 0.412$ & $0.84 \pm 0.881$ \\
\hline & Junior & $100(26.5)$ & $2.420 \pm 1.659$ & $1.02 \pm 0.899$ & $0.43 \pm 0.856$ & $0.15 \pm 0.479$ & $0.82 \pm 0.903$ \\
\hline & Senior & $26(6.9)$ & $2.270 \pm 1.373$ & $1.12 \pm 0.952$ & $0.58 \pm 0.703$ & $0.19 \pm 0.491$ & $0.38 \pm 0.571$ \\
\hline & Missing & 4 & & & & & \\
\hline \multirow[t]{8}{*}{ Age } & 20 years old & $114(30.2)$ & $2.167 \pm 1.310$ & $0.79 \pm 0.722$ & $0.41 \pm 0.714$ & $0.15 \pm 0.382$ & $0.82 \pm 0.736$ \\
\hline & 21 & $80(21.2)$ & $2.388 \pm 1.555$ & $0.78 \pm 0.779$ & $0.55 \pm 0.855$ & $0.09 \pm 0.363$ & $0.93 \pm 0.104$ \\
\hline & 22 & $51(13.5)$ & $2.608 \pm 2.050$ & $1.10 \pm 0.922$ & $0.43 \pm 0.700$ & $0.14 \pm 0.530$ & $1.03 \pm 0.144$ \\
\hline & 23 & $51(13.5)$ & $2.177 \pm 1.600$ & $0.80 \pm 0.825$ & $0.43 \pm 0.831$ & $0.20 \pm 0.530$ & $0.74 \pm 0.104$ \\
\hline & 24 & $41(10.9)$ & $2.317 \pm 1.312$ & $1.10 \pm 0.768$ & $0.46 \pm 0.840$ & $0.22 \pm 0.475$ & $0.55 \pm 0.086$ \\
\hline & 25 & $26(6.9)$ & $2.462 \pm 1.816$ & $1.19 \pm 1.132$ & $0.42 \pm 0.920$ & $0.12 \pm 0.431$ & $1.12 \pm 0.219$ \\
\hline & 26 and above & $14(3.7)$ & $2.429 \pm 1.604$ & $0.93 \pm 0.830$ & $0.71 \pm 0.825$ & $0.07 \pm 0.267$ & $0.83 \pm 0.221$ \\
\hline & Missing & 4 & & & & & \\
\hline \multirow{5}{*}{ Place of residence } & Live in board and lodging & $4(1.1)$ & $2.000 \pm 1.414$ & $0.25 \pm 0.500$ & $0.00 \pm 0.00$ & $0.25 \pm 0.500$ & $1.50 \pm 1.291$ \\
\hline & Live alone & $267(71.4)$ & $2.296 \pm 1.504$ & $0.95 \pm 0.828$ & $0.42 \pm 0.748$ & $0.15 \pm 0.439$ & $0.78 \pm 0.812$ \\
\hline & School dormitory & $16(4.3)$ & $2.875 \pm 2.825$ & $1.06 \pm 1.063$ & $0.69 \pm 0.946$ & $0.19 \pm 0.544$ & $0.94 \pm 1.063$ \\
\hline & Live with parents & $87(23.3)$ & $2.310 \pm 1.458$ & $0.74 \pm 0.784$ & $0.60 \pm 0.882$ & $0.13 \pm 0.398$ & $0.85 \pm 0.870$ \\
\hline & Missing & 7 & & & & & \\
\hline \multirow[t]{3}{*}{ Do you smoke? } & Yes & $74(20.7)$ & $2.432 \pm 1.745$ & $1.22 \pm 0.815^{a}$ & $0.26 \pm 0.598^{a}$ & $0.20 \pm 0.496$ & $0.76 \pm 0.948$ \\
\hline & No & $283(79.3)$ & $2.307 \pm 1.507$ & $0.83 \pm 0.831^{b}$ & $0.50 \pm 0.809^{b}$ & $0.14 \pm 0.436$ & $0.84 \pm 0.825$ \\
\hline & Missing & 24 & & & & & \\
\hline
\end{tabular}

${ }_{\mathrm{a}, \mathrm{b}}$ indicate significant differences in column for the category. ${ }^{*}$ caffeine was consumed more than twice daily by respondents. 
Table 2. Characteristics of the respondents regarding their caffeinated beverage consumption.

\begin{tabular}{|c|c|c|c|}
\hline $\begin{array}{l}\text { Caffeinated Beverage } \\
\text { Consumption Behaviors }\end{array}$ & & Frequency & Valid Percentage $(\%)$ \\
\hline \multirow{5}{*}{$\begin{array}{l}\text { Major caffeinated beverages consumed a } \\
\text { day (multiple answers) }\end{array}$} & Coffee & 175 & 45.4 \\
\hline & Tea & 30 & 7.79 \\
\hline & Energy drinks & 25 & 6.5 \\
\hline & Coffee and tea & 53 & 13.77 \\
\hline & Soft drinks and others & 102 & 26.49 \\
\hline \multirow{5}{*}{ Average coffee consumption a day } & 0 & 131 & 34.4 \\
\hline & 1 & 178 & 46.7 \\
\hline & 2 & 55 & 14.4 \\
\hline & 3 & 13 & 3.4 \\
\hline & 4 and above & 4 & 1.0 \\
\hline \multirow{5}{*}{ Average tea consumption a day } & 0 & 254 & 66.7 \\
\hline & 1 & 96 & 25.2 \\
\hline & 2 & 19 & 5.0 \\
\hline & 3 & 7 & 1.8 \\
\hline & 4 and above & 5 & 1.3 \\
\hline \multirow{5}{*}{ Average energy drinks consumption a day } & 0 & 337 & 88.5 \\
\hline & 1 & 33 & 8.7 \\
\hline & 2 & 10 & 2.6 \\
\hline & 3 & 1 & 0.3 \\
\hline & 4 and above & 0 & 0 \\
\hline \multirow{5}{*}{$\begin{array}{l}\text { Average soft drinks and others } \\
\text { consumption a day }\end{array}$} & 0 & 152 & 39.9 \\
\hline & 1 & 165 & 43.3 \\
\hline & 2 & 49 & 12.9 \\
\hline & 3 & 10 & 2.6 \\
\hline & 4 and above & 5 & 1.3 \\
\hline \multirow{7}{*}{$\begin{array}{l}\text { Major times for consuming caffeinated } \\
\text { beverages (multiple answers) }\end{array}$} & 07-10 & 28 & 6.3 \\
\hline & $10-12$ & 21 & 4.7 \\
\hline & $12-14$ & 90 & 20.1 \\
\hline & $14-16$ & 109 & 24.4 \\
\hline & $16-18$ & 59 & 13.2 \\
\hline & $18-20$ & 66 & 14.8 \\
\hline & After 20 & 74 & 16.6 \\
\hline
\end{tabular}

\subsection{Reliability and Validity of the Measurements}

Exploratory factor analysis was conducted for the 36 items adopted from previous studies [30,31] (Table 3). Six factors were extracted and both the variances and Eigen values for the factors showed satisfactory reliability (Table 4$)$. The six factors were as follows: F1: sensory aspects $(\alpha=0.888)$, F2: alertness $(\alpha=0.882)$, F3: social aspects $(\alpha=0.904)$, F4: health benefit $(\alpha=0.843)$, F5: mood $(\alpha=0.912)$, and F6: habit $(\alpha=0.853)$. For the habit factor, excluding Question 30 increased the reliability from 0.782 to 0.853 , hence the question was omitted. Correlations among the six factors were examined and indicated satisfactory validity (Table 5). All factors were significant at the 0.01 level. 
Table 3. Measurement items for motives for caffeine consumption questionnaire.

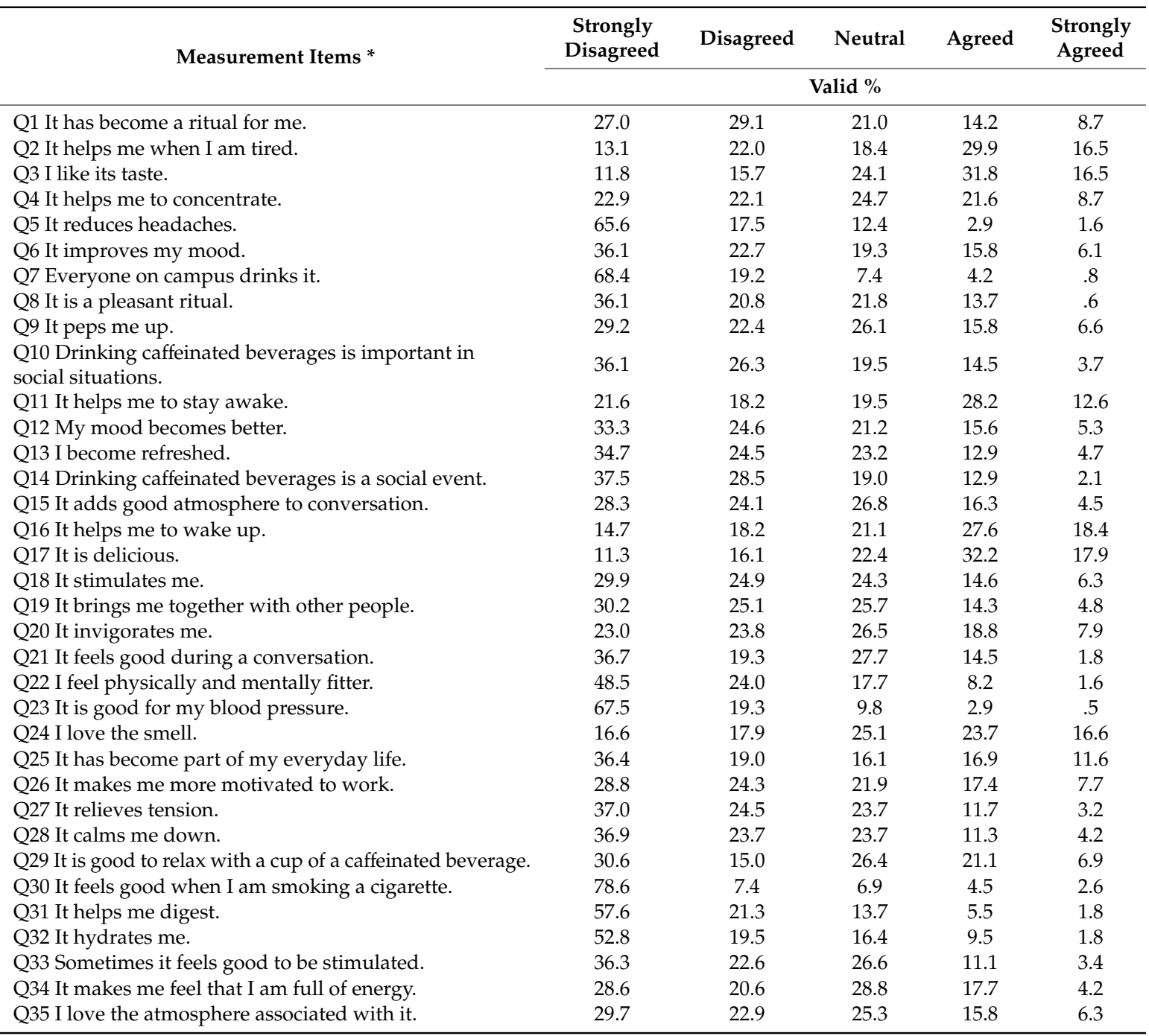

* 5-point Likert scales (1: strongly disagreed $\sim 5$ : strongly agreed).

Table 4. Exploratory factor analysis of the motivations for consuming caffeinated beverages $(n=381)$.

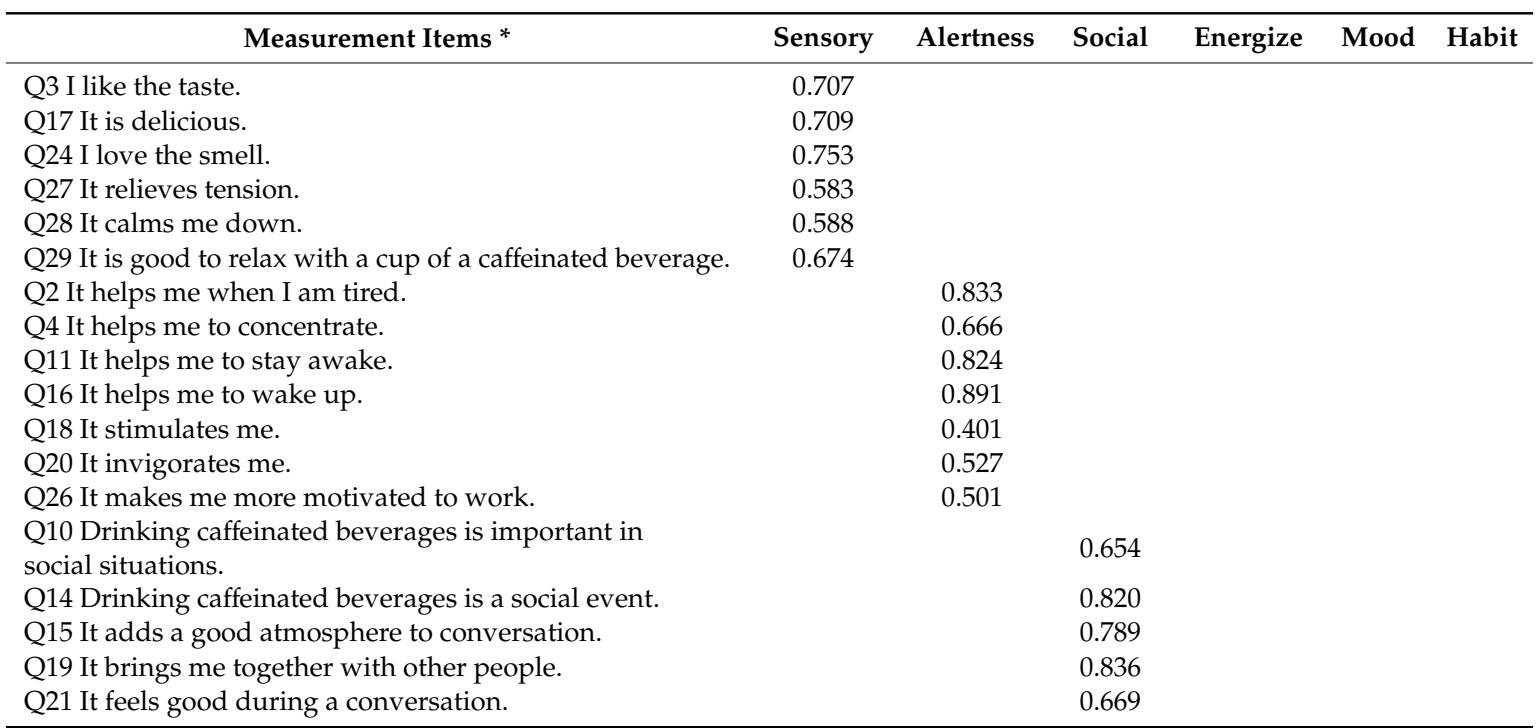


Table 4. Cont.

\begin{tabular}{|c|c|c|c|c|c|c|}
\hline Measurement Items * & Sensory & Alertness & Social & Energize & Mood & Habit \\
\hline Q35 I love the atmosphere associated with it. & & & 0.503 & & & \\
\hline Q5 It reduces headaches. & & & & 0.620 & & \\
\hline Q7 Everyone on campus drinks it. & & & & 0.432 & & \\
\hline Q22 I feel physically and mentally fitter. & & & & 0.604 & & \\
\hline Q23 It is good for my blood pressure. & & & & 0.648 & & \\
\hline Q31 It helps me digest. & & & & 0.597 & & \\
\hline Q32 It hydrates me. & & & & 0.509 & & \\
\hline Q33 Sometimes it feels good to be stimulated. & & & & 0.721 & & \\
\hline Q6 It improves my mood. & & & & & 0.712 & \\
\hline Q9 It peps me up. & & & & & 0.575 & \\
\hline Q12 My mood becomes better. & & & & & 0.678 & \\
\hline Q13 I become refreshed. & & & & & 0.635 & \\
\hline Q33 Sometimes it feels good to be stimulated. & & & & & 0.465 & \\
\hline Q34 It makes me feel that I am full of energy. & & & & & 0.565 & \\
\hline Q1 It has become a ritual for me. & & & & & & 0.593 \\
\hline Q8 It is a pleasant ritual. & & & & & & 0.489 \\
\hline Q25 It has become part of my everyday life. & & & & & & 0.544 \\
\hline Q30 It feels good when I am smoking a cigarette. & & & & & & 0.543 \\
\hline Eigen value & 4.806 & 4.452 & 4.439 & 4.352 & 4.313 & 1.982 \\
\hline
\end{tabular}

* 5-point Likert scales (1: strongly disagreed $\sim$ 5: strongly agreed).

Table 5. Correlations between the factors and internal consistency.

\begin{tabular}{|c|c|c|c|c|c|c|}
\hline & Sensory & Alertness & Social & Energize & Mood & Habit \\
\hline Sensory & & & & & & \\
\hline Alertness & $0.507^{* *}$ & & & & & \\
\hline Social & $0.605^{* *}$ & $0.476^{* *}$ & & & & \\
\hline Health benefits & 0.600 ** & 0.440 ** & $0.604^{* *}$ & & & \\
\hline Mood & $0.725 * *$ & $0.691^{* *}$ & $0.636^{* *}$ & $0.650 * *$ & & \\
\hline Habit & $0.689 * *$ & $0.567^{* *}$ & $0.595^{* *}$ & $0.546^{* *}$ & $0.696^{* *}$ & \\
\hline Cronbach's alphas & 0.888 & 0.882 & 0.904 & 0.843 & 0.912 & 0.853 \\
\hline
\end{tabular}

\subsection{Motivations Influencing Caffeinated Beverage Consumption}

Multiple regression analysis was conducted to determine the effectiveness of motivations for caffeinated beverage consumption. Six motivations were regressed on the frequencies of the four categories of caffeinated beverage (coffee, tea, energy drinks, soft drinks and others). Coffee consumption was affected by a desire for alertness $(B=0.107, \mathrm{SE}=0.049, \mathrm{t}=2.181, p<0.05)$ and habit $(\mathrm{B}=0.345$, $\mathrm{SE}=0.046, \mathrm{t}=7.428, p<0.001)$ (Table 6). Tea consumption was influenced by social motivations $(\mathrm{B}=0.142, \mathrm{SE}=0.060, \mathrm{t}=2.357, p<0.05)$ (Table 7). Both a desire for alertness $(\mathrm{B}=0.100, \mathrm{SE}=0.034$, $\mathrm{t}=2.966, p<0.01)$ and health benefits $(\mathrm{B}=0.120, \mathrm{SE}=0.051, \mathrm{t}=2.345, p<0.05)$ significantly impacted energy drink consumption (Table 8). Soft drinks and others were not significantly influenced by any motivations (Table 9).

The motivations for caffeinated beverage consumption were compared according to the demographic characteristics of the respondents. Independent $t$-tests showed the six motivations were not significantly different by gender. ANOVA and Tukey's test were conducted to identify differences among the effect of years of college on the motivations. Alertness as a motivation showed significant differences among students $(\mathrm{F}=4.223, p<0.01)$. Seniors $(\mathrm{M}=2.862$, $\mathrm{SD}=1.132)$ were more likely to consume caffeinated beverage for alertness than freshmen $(\mathrm{M}=2.216, \mathrm{SD}=0.949)$ and sophomores $(\mathrm{M}=2.181, \mathrm{SD}=0.931)$. Only habit as a motivation was significantly different among respondents with different years of college $(\mathrm{F}=4.760, p<0.01)$. Habit as a motivation for freshmen $(\mathrm{M}=2.231, \mathrm{SD}=1.112)$ was significantly different from that for juniors $(\mathrm{M}=2.677, \mathrm{SD}=1.169)$ and seniors $(\mathrm{M}=2.949, \mathrm{SD}=1.501)$, with $p=0.05$. Independent $t$-tests were conducted on comparisons of motivations according to the smoking status. Sensory aspects $(t=1.982, p=0.05)$, health benefits 
$(\mathrm{t}=2.089, p<0.05)$, and habit $(\mathrm{t}=2.426, p<0.05)$ showed significant differences. Sensory aspects $(\mathrm{M}=3.00, \mathrm{SD}=1.032)$, health benefits $(\mathrm{M}=1.798, \mathrm{SD}=0.08)$, and habit $(\mathrm{M}=2.748, \mathrm{SD}=0.131)$ were greater motivations for smokers than for non-smokers (sensory: $\mathrm{M}=2.734, \mathrm{SD}=0.059$, health benefits: $\mathrm{M}=1.610, \mathrm{SD}=1.001$, habit: $\mathrm{M}=2.387, \mathrm{SD}=1.171)$.

Table 6. Results of regression analysis of motivations influencing coffee consumption.

\begin{tabular}{ccccc}
\hline Model & \multicolumn{2}{c}{ Unstandardized } & & \\
& B & SE & St.d Beta & t-Value \\
\hline Constant & -0.463 & 0.122 & & $-3.793^{* * *}$ \\
Sensory & 0.108 & 0.055 & 0.133 & 1.944 \\
Alertness & 0.107 & 0.049 & 0.129 & $2.181^{*}$ \\
Social & 0.023 & 0.052 & 0.027 & 0.444 \\
Energize & 0.011 & 0.075 & 0.009 & 0.148 \\
Mood & -0.072 & 0.066 & -0.088 & -1.093 \\
Habit & 0.345 & 0.046 & 0.489 & $7.428^{* * *}$ \\
\hline $394, p=0.000, \mathrm{R}=0.626, \mathrm{R}^{2}=0.392$, Adjusted $\mathrm{R}^{2}=0.382 .{ }^{*} p<0.05, * * *$ & $p<001$.
\end{tabular}

Table 7. Results of regression analysis of motivations influencing tea consumption.

\begin{tabular}{ccccc}
\hline Model & \multicolumn{2}{c}{ Unstandardized } & & \\
& B & SE & St.d Beta & t-Value \\
\hline Constant & 0.309 & 0.143 & & 2.162 \\
Sensory & 0.048 & 0.065 & 0.064 & 0.744 \\
Alertness & -0.056 & 0.058 & -0.073 & -0.979 \\
Social & 0.142 & 0.060 & 0.180 & $2.357 *$ \\
Energize & 0.098 & 0.088 & 0.086 & 1.114 \\
Mood & -0.115 & 0.077 & -0.152 & -1.490 \\
Habit & -0.025 & 0.054 & -0.039 & -0.467 \\
\hline $\mathrm{F}=2.070, p=0.560, \mathrm{R}=0.188, \mathrm{R}^{2}=0.035$, Adjusted $\mathrm{R}^{2}=0.018 .{ }^{*} p<0.05$.
\end{tabular}

Table 8. Results of regression analysis of motivations that influence energy drink consumption.

\begin{tabular}{ccccc}
\hline Model & \multicolumn{4}{c}{ Unstandardized } \\
& B & SE & St.d Beta & t-Value \\
\hline Constant & 0.045 & 0.083 & & 0.534 \\
Sensory & -0.050 & 0.038 & -0.113 & -1.330 \\
Alertness & 0.100 & 0.034 & 0.219 & $2.966^{* *}$ \\
Social & -0.006 & 0.035 & -0.013 & -0.176 \\
Health benefits & 0.120 & 0.051 & 0.180 & $2.345^{*}$ \\
Mood & -0.042 & 0.045 & -0.094 & -0.931 \\
Habit & -0.046 & 0.032 & -0.120 & -1.453 \\
$\mathrm{~F}=2.925, p=0.009, \mathrm{R}=0.222, \mathrm{R}^{2}=0.049$, Adjusted $\mathrm{R}^{2}=0.032 .^{*} p<0.05,{ }^{* *} p<0.01$.
\end{tabular}

Table 9. Results of regression analysis of motivations that influence the consumption of soft drinks and others.

\begin{tabular}{|c|c|c|c|c|}
\hline \multirow[t]{2}{*}{ Model } & \multicolumn{2}{|c|}{ Unstandardized } & \multirow[b]{2}{*}{ St.d Beta } & \multirow[b]{2}{*}{ t-Value } \\
\hline & B & SE & & \\
\hline Constant & 0.889 & 0.162 & & $5.473^{* * *}$ \\
\hline Sensory & -0.067 & 0.074 & -0.078 & -0.904 \\
\hline Alertness & -0.068 & 0.065 & -0.078 & -1.039 \\
\hline Social & 0.064 & 0.069 & 0.072 & 0.937 \\
\hline Health benefits & 0.151 & 0.100 & 0.118 & 1.516 \\
\hline Mood & 0.032 & 0.088 & 0.038 & 0.368 \\
\hline Habit & -0.060 & 0.062 & -0.081 & -0.966 \\
\hline
\end{tabular}




\subsection{Quality of Sleep and Caffeinated Beverage Consumption}

The sleep quality of the respondents was measured using PSQI. The average number of hours the students spent sleeping was more than $6(\mathrm{M}=6.6, \mathrm{SD}=1.640)$ and the average length of time they spent in bed before falling asleep was $23.65 \mathrm{~min}(\mathrm{SD}=20.166)$. The PSQI score was calculated as described in a previous study [32]. The average PSQI score was $5.86(\mathrm{SD}=3.064)$, ranging from 0 to 17. The sleep quality had no differences by gender or grade but was affected by smoking $(t=2.621$, $p=0.01)$. ANOVA showed that non-smokers had a lower PSQI $(\mathrm{M}=5.63, \mathrm{SE}=2.88)$ than smokers $(\mathrm{M}=6.83, \mathrm{SE}=3.67)$. In addition, the correlation between the consumption of caffeinated beverages and PSQI scores was significant (Pearson's correlation $=0.126, p<0.05$ ).

\section{Discussion}

The results of this study indicated that the motivations for caffeinated beverage consumption were sensory effects, alertness, social factors, health benefits, mood, and habit, similar to the results of a previous study [30]. Interestingly, the motivations for the consumption of each caffeinated beverage were different. Coffee drinkers were motivated by a desire for alertness, which is one of the appealing characteristics of caffeine, and drinking coffee was considered a habitual behavior. Tea consumption was motivated by socialization. In this study cohort, tea was less popular than coffee and soft drinks. Tea may not appeal to college students sufficiently for them to be motivated by its caffeine content; however, socializing with others motivated college students to consume tea. This result suggests that socialization may require a compromise regarding the selection of beverages since tea brewed in a pot can serve a group of people with the adjustment of the tea leaves. It has been reported that energy drinks are consumed for various reasons [10]. This study found that college students chose energy drinks due to their well-known reputation of inducing alertness and health benefits. Previous results suggested that college students expect strong caffeine effects from energy drinks and consume them as health aids for digestion, blood pressure, headache, etc. [7]. It may be that college students consider energy drinks as an effective dose of caffeine that can provide health benefits; for example, an increased heart rate improves blood circulation, which may help dieters lose weight [33]. However, it appears that caffeinated beverage consumers do not know or misjudge the adverse effects of caffeine in energy drinks. In order to inform college students about how caffeine works in the human body and the associated mechanisms, appropriate educational intervention should be implemented [10]. Soft drinks and others were more popular than energy drinks and tea but less popular than coffee; however, there were no motivations for consuming soft drinks and others. This can be interpreted to mean that college students do not associate soft drinks with caffeine, possibly due to a lack of awareness of the features of caffeine and its products [10]. College students consume caffeinated beverage products with different motivations, but they appear to be more aware of the positive effects of caffeine than the negative effects. As mentioned earlier, appropriate and effective educational intervention can help highlight both the positive and negative aspects of caffeine consumption, which will help students make smart choices about caffeinated beverages. Effective educational intervention should be developed taking into account the idiosyncratic characteristics of caffeinated beverage consumption [34]. More detailed interventions will facilitate healthier caffeinated beverage consumption behavior. With such educational invention, labels on products are necessary to inform consumers about the amount of caffeine in each product, similar to nutritional fact labeling. This will help consumers be more informed about caffeine in the products.

Smokers had a higher intake of coffee than non-smokers, who had a higher intake of tea; however, no differences were found in the intake of energy drinks and soft drinks unlike in a previous study [11]. These results suggest that smokers may prefer coffee when they smoke. Smokers might enjoy the full power of the enhanced caffeine effect physically or emotionally. Hence, physiological, cognitive, and environmental factors may all contribute to the association between smoking and caffeine intake [11]. Labels cautioning users that coffee consumption while smoking can increase the effect of caffeine may be beneficial to educate and warn consumers not to abuse cigarettes and coffee. 
Measuring the sleep quality of college students using PSQI showed that they had some difficulties sleeping. PSQI scores $>5$ indicate the individual is having some difficulties sleeping, representing poor sleep quality [32]. The average sleep duration, which was almost 7 hours, was moderate and the time spent in bed before falling asleep was $23 \mathrm{~min}$, similar to the results from insomniac adults in Korea [35]. Sleep quality may be poor and the caffeinated beverage consumption was correlated with sleep quality, similar to previous studies $[18,22,23,36]$. However, a study conducted in three European nations showed that caffeine did not cause difficulties in sleep after controlling for some demographics [37]. There may be other factors that affect sleep quality such as electronic device usage, lifestyle, and fast food consumption. Furthermore, sleep quality did not differ by gender unlike previous findings [29]. Interestingly, non-smokers had better sleep quality than smokers though gender and grade showed no differences in sleep quality. Smokers may have different reasons for poor sleep quality regardless of caffeinated beverage consumption. There may also be confounding effects from other elements since this was a self-reported survey and the number of variables examined in the questionnaire was limited, primarily focusing on the motivations for caffeinated beverage consumption and sleep quality.

Caffeinated beverages are prevalent in daily life and have become a normal part of life. College students consume caffeinated beverage from various sources and coffee was the most common caffeine product consumed by the respondents in this study, followed by soft drinks, tea, and energy drinks, similar to the pattern reported in previous studies $[4,11]$. In the general population, the frequency of tea intake is higher than that of energy drinks [4]. However, the respondents in this study, college students, had a higher intake of energy drinks than tea. Caffeinated beverage consumption comparisons by gender showed that male students had more coffee intake than female students, similar to a previous report that adult men (over 18 years) consumed more caffeine from beverages than adult women [4]. Adolescents showed a similar pattern [23], but another study found that women consume more caffeinated drinks than men [11]. The results of this study indicated that the majority of smokers were male students and this group is more likely to consume coffee while smoking cigarettes, a correlation extensively reported in the literature [11,34].

\section{Limitations}

The effects of caffeinated beverages may be better understood in combination with other food-related activities and individual lifestyles [22]. There are some factors that affect sleep other than caffeine. For example, noise, artificial light, and diet might interfere with sleep and these factors should be included in future research. In addition, electronic media usage should be included in a future study.

This study did not measure the amount of caffeine intake. Rather, it focused on the frequency of consumption and motivations related to smoking and sleep quality. The caffeine content of products depends on the method of preparation, brand, and serving size; hence, variations exist [1]. Calculating the amount of caffeine in products would be unreliable in a self-reported survey; therefore, this study did not assess the actual caffeine amount. Future observation or laboratory studies to examine the retail caffeinated beverage products available in Korea may be needed. Specific cases of caffeinated beverage consumption, for example, personal, physical, and societal environmental factors should be investigated to assess consumer behaviors regarding caffeine. In addition, this study was conducted on college students in Korea and the generalization of the results may be limited.

\section{Conclusions}

The purpose of this study was to conduct specific analyses of the behavioral characteristics of caffeine consumption in accordance with motivation. Several distinct features were identified in terms of caffeinated beverage motivation and caffeinated beverage consumption. Respondents had poor sleep quality, and relationships between caffeinated beverage consumption and sleep quality were found using PSQI. Smokers had higher coffee intake and lower tea consumption than non-smokers. In addition, smokers had poor sleep quality. Interactions between caffeinated beverage consumption 
and smoking had no effect on sleep quality. College students appeared to be poorly informed about the characteristics of caffeine; therefore, appropriate educational intervention should be implemented. Providing labeling information about caffeine content and the daily limit may be a good educational tool for consumers. Moreover, tailoring detailed information for specific cases such as the fact that consuming coffee while smoking increases the effect of caffeine should be applied as an educational tool and labeling policy.

Funding: This research is based support of Woosong University Academic Research.

Conflicts of Interest: The authors declare no conflict of interest.

\section{References}

1. Nawrot, P.; Jordan, S.; Eastwood, J.; Rotstein, J.; Hugenholtz, A.; Feeley, M. Effects of caffeine on human health. Food Addit. Contam. 2003, 20, 1-30. [CrossRef] [PubMed]

2. Yoon, M.-H.; Lee, M.J.; Hwang, S.-I.; Moon, S.-K.; Kim, J.-K.; Jeong, I.-H.; Yim, J.-R. A evaluation of the caffeine contents in commercial foods. J. Food Hygine Saf. 2001, 16, 259-299.

3. Krieger, D.R.; Kalman, D.S.; Feldman, S.; Arnillas, L.; Goldberg, D.; Gisbert, O.; Nader, S. The Safety, Pharmacokinetics, and Nervous System Effects of Two Natural Sources of Caffeine in Healthy Adult Males. Cts: Clin. Transl. Sci. 2016, 9, 246-251. [CrossRef] [PubMed]

4. Fulgoni, V.L., 3rd; Keast, D.R.; Lieberman, H.R. Trends in intake and sources of caffeine in the diets of US adults: 2001-2010. Am. J. Clin. Nutr. 2015, 101, 1081-1087. [CrossRef]

5. Lee, J.S.; Park, H.S.; Han, S.H.; Geukgun, T.N.; Park, E.J. Study on relationship between caffeine intake level and metabolic syndrome and related diseases in Korean adults: 2013 2016 Korea National Health and Nutrition Examination Survey. J. Nutr. Health 2019, 52, 227-241.

6. Baek, J.M.; Song, J.Y.; Lee, S.J.; Park, E.K.; Jeung, I.C.; Kim, C.J.; Lee, Y.S. Caffeine Intake Is Associated with Urinary Incontinence in Korean Postmenopausal Women: Results from the Korean National Health and Nutrition Examination Survey. PLoS ONE 2016, 11, e0149311. [CrossRef]

7. Heckman, M.A.; Weil, J.; De Mejia, E.G. Caffeine (1,3, 7-trimethylxanthine) in Foods: A Comprehensive Review on Consumption, Functionality, Safety, and Regulatory Matters. J. Food Sci. 2010, 75, R77-R87. [CrossRef]

8. Mitchell, D.C.; Knight, C.A.; Hockenberry, J.; Teplansky, R.; Hartman, T.J. Beverage caffeine intakes in the U.S. Food Chem. Toxicol. 2014, 63, 136-142. [CrossRef]

9. Han, J.H.; Kim, D.K. The Effect of Selection Attributes of HMR Convenience Store Dosirak and Chain Dosirak on Relationship Orientation. J. Tour. Leis. Res. 2019, 31, 259-276. [CrossRef]

10. Attila, S.; Çakir, B. Energy-drink consumption in college students and associated factors. Nutrition 2011, 27, 316-322. [CrossRef]

11. Mahoney, C.R.; Giles, G.E.; Marriott, B.P.; Judelson, D.A.; Glickman, E.L.; Geiselman, P.J.; Lieberman, H.R. Intake of caffeine from all sources and reasons for use by college students. Clin. Nutr. 2019, 38, 668-675. [CrossRef]

12. Rivers, W.H.R.; Webber, H.N. The action of caffeine on the capacity for muscular work. J. Physiol. 1907, 36, 33-47. [CrossRef] [PubMed]

13. Desbrow, B.; Leveritt, M. Well-Trained Endurance Athletes' Knowledge, Insight, and Experience of Caffeine Use. Int. J. Sport Nutr. Exerc. Metab. 2007, 17, 328-339. [CrossRef] [PubMed]

14. Wolk, B.J.; Ganetsky, M.; Babu, K.M. Toxicity of energy drinks. Curr. Opin. Pediatr. 2012, 24, $243-251$. [CrossRef] [PubMed]

15. Ribeiro, J.A.; Sebastiao, A.M. Caffeine and adenosine. J. Alzheimers Dis 2010, 20 (Suppl. 1), S3-S15. [CrossRef] [PubMed]

16. Van Dongen, H.P.; Price, N.J.; Mullington, J.M.; Szuba, M.P.; Kapoor, S.C.; Dinges, D.F. Caffeine eliminates psychomotor vigilance deficits from sleep inertia. Sleep 2001, 24, 813-819. [CrossRef]

17. Rogers, P.; Richardson, N.; Elliman, N. Overnight caffeine abstinence and negative reinforcement of preference for caffeine-containing drinks. Psychopharmacology 1995, 120, 457-462. [CrossRef]

18. O'Callaghan, F.; Muurlink, O.; Reid, N. Effects of caffeine on sleep quality and daytime functioning. Risk Manag. Healthc. Policy 2018, 11, 263-271. [CrossRef] 
19. Orbeta, R.L.; Overpeck, M.D.; Ramcharran, D.; Kogan, M.D.; Ledsky, R. High caffeine intake in adolescents: Associations with difficulty sleeping and feeling tired in the morning. J. Adolesc. Health 2006, 38, 451-453. [CrossRef]

20. Nehlig, A.; Daval, J.-L.; Debry, G. Caffeine and the central nervous system: Mechanisms of action, biochemical, metabolic and psychostimulant effects. Brain Res. Rev. 1992, 17, 139-170. [CrossRef]

21. Bonnet, M.H.; Arand, D.L. Hyperarousal and insomnia: State of the science. Sleep Med. Rev. 2010, 14, 9-15. [CrossRef] [PubMed]

22. Landolt, H.-P.; Werth, E.; Borbély, A.A.; Dijk, D.-J. Caffeine intake (200 mg) in the morning affects human sleep and EEG power spectra at night. Brain Res. 1995, 675, 67-74. [CrossRef]

23. Ramakrishnan, S.; Wesensten, N.J.; Kamimori, G.H.; Moon, J.E.; Balkin, T.J.; Reifman, J. A Unified Model of Performance for Predicting the Effects of Sleep and Caffeine. Sleep 2016, 39, 1827-1841. [CrossRef] [PubMed]

24. Nuri, J.; Aeri, L.; Inkyung, B. Associations of Caffeinated Beverage Consumption and Screen Time with Excessive Daytime Sleepiness in Korean High School Students. Clin. Nutr. Res. 2017, 6, 55.

25. Korea Ministry of Food and Drug Safety. Recommended Daily Allowance for Caffeine. Available online: https://www.mfds.go.kr/brd/m_99/down.do?brd_id=ntc0021\&seq=44023\&data_tp=A\&file_seq=2 (accessed on 17 January 2020).

26. European Food Safety Authority. EFSA Panel on Dietetic Products, Nutrition and Allergies (NDA). Draft scientific opinion on the safety of caffeine. EFSA J. 2015, 13, 1-120.

27. Giannotti, F.; Cortesi, F.; Sebastiani, T.; Ottaviano, S. Circadian preference, sleep and daytime behaviour in adolescence. J. Sleep Res. 2002, 11, 191-199. [CrossRef] [PubMed]

28. European Commisions. Regulation (EU) No 1169/2011 of the European parliament and of the council of 25 October 2011 on the provision of food information to consumers, amending Regulations (EC) No 1924/2006 and (EC) No 1925/2006 of the of the European Parliament and of the Council, and repealing Commission Directive 87/250/EEC, Council Directive 90/496/EEC, Commission Directive 1999/ 10/EC, Directive 2000/13/EC of the European Parliament and of the Council, Commission Directives 2002/67/EC and 2008/5/EC and Commission Regulation (EC) No 608/ 2004. Off. J. Eur. Comm. 2011, L304, 18-63.

29. Lim, H.S.; Hwang, J.Y.; Choi, J.C.; Kim, M. Assessment of caffeine intake in the Korean population. Food Addit. Contam. Part A Chem. Anal. Control Expo. Risk Assess. 1786, 32, 1786-1798. [CrossRef]

30. Ágoston, C.; Urbán, R.; Király, O.; Griffiths, M.D.; Rogers, P.J.; Demetrovics, Z. Why Do You Drink Caffeine? The Development of the Motives for Caffeine Consumption Questionnaire (MCCQ) and Its Relationship with Gender, Age and the Types of Caffeinated Beverages. Int. J. Ment Health Addict. 2018, 16, 981-999. [CrossRef]

31. Landrum, R.E. College students' use of caffeine and its relationship to personality. Coll. Stud. J. 1992, 26, 151-155.

32. Buysse, D.J.; Reynolds, C.F.; Monk, T.H.; Berman, S.R.; Kupfer, D.J. The Pittsburgh sleep quality index: A new instrument for psychiatric practice and research. Psychiatry Res. 1989, 28, 193-213. [CrossRef]

33. Jeffers, A.J.; Vatalaro Hill, K.E.; Benotsch, E.G. Energy Drinks, Weight Loss, and Disordered Eating Behaviors. J. Am. Coll. Health 2014, 62, 336-342. [CrossRef] [PubMed]

34. Das-Friebel, A.; Perkinson-Gloor, N.; Brand, S.; Dewald-Kaufmann, J.F.; Grob, A.; Wolke, D.; Lemola, S. A pilot cluster-randomised study to increase sleep duration by decreasing electronic media use at night and caffeine consumption in adolescents. Sleep Med. 2019, 60, 109-115. [CrossRef] [PubMed]

35. Shin, S.J.; Hwang, E.H. Eunhee A study on the subjective and objective sleep of the insomniac adults. Korean J. Ehalth Promot. Dis. Prev. 2008, 8, 141-149.

36. Subin, P.; Yeeun, L.; Lee, J.H. Association between energy drink intake, sleep, stress, and suicidality in Korean adolescents: Energy drink use in isolation or in combination with junk food consumption. Nutr. J. 2016, 15, 1-8. [CrossRef]

37. Janson, C.; Gislason, T.; De Backer, W.; Plaschke, P.; Bjornsson, E.; Hetta, J.; Kristbjarnason, H.; Vermeire, P.; Boman, G. Prevalence of sleep disturbances among young adults in three European countries. Sleep 1995, 18, 589-597.

(C) 2020 by the author. Licensee MDPI, Basel, Switzerland. This article is an open access article distributed under the terms and conditions of the Creative Commons Attribution (CC BY) license (http://creativecommons.org/licenses/by/4.0/). 